\title{
Molecular recognition characteristics in the insulin-like growth factor (IGF)-insulin-like growth factor binding protein -3/5 (IGFBP-3/5) heparin axis
}

\author{
James Beattie, Kirsten Phillips, John H Shand, Malgorzata Szymanowska, David J Flint \\ and Gordon J Allan
}

Department of Molecular Recognition, Hannah Research Institute, Ayr KA6 5HL, Scotland

(Requests for offprints should be addressed to James Beattie; Email: beattiej@ hri.sari.ac.uk)

\begin{abstract}
Insulin-like growth factor binding proteins (IGFBPs) -3 and -5 are known to interact with various components of the extracellular matrix (ECM; e.g. heparin and heparan sulphate) and this interaction is believed to affect the affinity of both IGFBP species for their cognate ligands - IGF-I and -II. There is little detail on the nature of the molecular complex formed between ECM components, IGFBPs and IGFs although the glycosaminoglycan (GAG) heparin has been reported to reduce the affinity of IGFBP-5 for IGF-I. In order to investigate this phenomenon further, we have undertaken an extensive surface plasmon resonance based biosensor study to report the affinity of IGFBP-3 and -5 for binding heparin (22 and $7 \mathrm{nM}$ respectively). We have also shown that pre-complexation of IGFBP with IGF-I and -II inhibits the subsequent association of IGFBP with heparin and conversely that heparin complexation of IGFBP-3 and -5 inhibits IGFBP binding to biosensor surfaces containing immobilised IGF-I. In addition we have used both IGF-I and heparin coated biosensor surfaces in an attempt to build ternary IGF-IGFBP-heparin complexes in order to gain some insight into the nature of inhibition by heparin of IGFI-IGFBP complex formation. Our data lead us to conclude that the inhibition by heparin is partly competitive in nature, and that ternary complexes of IGF-IGFBP-heparin are either unable to form, or only form unstable transient complexes. The potential biological significance of our data is highlighted by the demonstration that IGF-I and IGF-II can displace endogenous IGFBP-5 from monolayer cultures of the mouse mammary epithelial cell line HC11.
\end{abstract}

Journal of Molecular Endocrinology (2005) 34, 163-175

\section{Introduction}

IGF-I and IGF-II are small polypeptides $(\sim 7.5 \mathrm{kDa})$ which play an important role in the growth, development and differentiation of several tissues. In vivo, the activity of IGFs is regulated by the high affinity interaction between these polypeptide growth factors and a family of six well-characterised IGFBPs (see Firth \& Baxter (2002) for a recent review). An obvious role for IGFBPs is the sequestration of IGFs from their cell surface receptor and a resultant inhibition of action of the growth factors. However, the IGFBPs display many more functions including IGF-independent effects (Ferry et al. 1999). Both IGF-dependent and -independent effects are regulated by a series of post-translational modifications including phosphorylation (Sakai et al. 2001), glycosylation (Baxter \& Firth 1995) and proteolysis (Bang 1995, Donnelly \& Holly 1996). Another major activity possessed by some IGFBPs is their ability to associate with glycosaminoglycans (GAGs), and other extracellular proteins and proteoglycans. This has been especially well reported for IGFBP-3 and IGFBP-5, the latter having been reported to bind hydroxyapatite (Campbell \& Andress 1997), vitronectin (Nam et al. 2002), thrombospondin and osteopontin (Nam et al. 2000), plasminogen activator inhibitor-I (PAI-I) (Nam et al. 1997) and importin $\beta$ (Schedlich et al. 2000) as well as the GAGs heparin, heparan sulphate and dermatan sulphate (Arai et al. 1994a).

The ability of IGFBP-5 to associate with heparin has important consequences for the formation of IGFBP-5IGF complexes and for the subsequent biological actions of these two proteins. It has been known for some time that heparin can dissociate IGF-I from binding protein (BP) complexes in serum (Clemmons et al. 1983) although a subsequent report suggested that this disruption occurred at the acid labile subunit (ALS)IGFBP interface but not at the IGFBP-IGF interface (Baxter 1990). The observation that heparin (and IGF-I) could release IGFBP-3 from the surface of human neonatal fibroblasts indicated the potential biological significance of this heparin-IGFBP-IGF molecular axis (Martin et al. 1992). The subsequent detection of heparin binding motifs in human, rat and bovine IGFBP-3 and 
-5 (amongst others) with the demonstration that pooled fractions from serum, containing different IGFBP species bound directly to a heparin affinity matrix, further demonstrated the potential physiological relevance of these interactions. In an elegant study by Arai et al. (1994b), heparin, heparan sulphate and the sulphated polysaccharide dextran sulphate were found to inhibit the interaction between IGFBP-3/5 and IGF-I, but not inhibit IGFBP-1, -2 or -4 binding to the growth factor. Scatchard analysis of the binding of labelled IGF-I and IGFBP-5 conducted in the presence of heparin indicated a 17-fold decrease in affinity between IGF-I and BP. In a further study the same group reported that human dermal fibroblast-derived IGFBP-5 was protected from proteolysis when sequestered by heparin, indicating a further GAG-derived method for manipulation of BP activity. Investigation at the molecular level of the interaction between heparin and IGFBP-5 has identified the region lying between residues 201 and 218 as the major heparin binding domain (Arai et al. 1996) and an extensive site-directed mutagenesis study within this region of the protein has indicated the importance of specific basic amino acid residues in binding to heparin (Parker et al. 1996). Sequence analysis of IGFBPs has also indicated the presence of an ' $\mathrm{S}$ type' heparin binding domain in the central region of some IGFBPs (Hodgkinson et al. 1994) and further work from our group has shown that there is also a central heparin binding site in IGFBP-5, involving the amino acids Arg136 and Arg137 (Song et al. 2001).

Although, as indicated above, heparin has been reported to reduce the affinity between IGF-I and IGFBP-5, there is very little information on the molecular nature of any putative tri-partite heparinIGFBP-IGF complex. Previous studies from our laboratory have indicated two residues in the $\mathrm{C}$-terminal region of IGFBP-5 (G203 and Q209) which are highly conserved in all BPs and act in concert with a hydrophobic pocket in the N-terminal domain to provide a high affinity IGF binding site (Shand et al. 2003, Song et al. 2000). The observation that these two highly conserved C-terminal residues are also in the region of the $\mathrm{C}$-terminal heparin binding domain led us to formulate the hypothesis that IGFBP-5 binding to heparin and to IGFs is mutually exclusive. In order to test this hypothesis we have conducted an extensive biosensor based study where we have carefully examined the kinetics and affinity of the interaction of both IGFBP-3 and -5 with heparin coated biosensor surfaces and examined the effects of pre-complexation of either of the IGFBPs with IGF-I and -II on subsequent interaction with heparin. Using an IGF-I biosensor surface we have also pre-complexed IGFBP-5 and -3 to heparin and examined the kinetics of the subsequent interaction between IGF-I and IGFBP-5 or -3. In addition, we have attempted to build IGF-IGFBP- heparin complexes using IGF-I and heparin biosensor surfaces. Finally, we have investigated the potential biological significance of our studies by examining the ability of IGFs to displace endogenous IGFBP-5 from monolayer cultures of the mouse mammary epithelial cell line HC11. In this present report we discuss our findings and draw some conclusions on the dynamics of IGF-IGFBP-heparin complexes.

\section{Materials and methods}

\section{Materials}

Recombinant mouse IGFBP-5 (mIGFBP-5) was expressed and purified as described previously (Allan et al. 2002). Commercial recombinant mIGFBP-5, mIGFBP-3 and mIGFBP-2, product nos 578-B5-025, 775-B3-025 and 797-B2-025 respectively, and monoclonal anti-mouse IGFBP-3 (MAB 775) were obtained from R\&D Systems Europe Ltd (Abingdon, Oxfordshire, UK). Sheep anti-mouse IGFBP-5 antisera was generated 'in house' and has been described previously (Tonner et al. 1997). Anti-bovine IGFBP-2 (Cat No. 06-107) was from Upstate (Milton Keynes, Buckinghamshire, UK). Animal/media grade human IGF-I (product no. $1 \mathrm{M} 001$ ) and IGF-II (product no. 0 M001) were from GroPep Ltd (Adelaide, Australia). Biotinylated-albumin conjugate (A-8549), biotinylatedalbumin-heparin conjugate $(\mathrm{H}-4016)$, bovine insulin (I-6634) and heparin (porcine intestinal mucosaGrade-II Na salt H-7005) were from Sigma (Poole, Dorset). Reagents for biosensor studies were supplied by BiaCore Ltd (Stevenage, Hertfordshire, UK). All other reagents were of analytical grade.

\section{Methods}

\section{Biosensor analysis}

All biosensor studies were performed on a fully automated BiaCore 3000 instrument (BiaCore, Stevenage, Hertfordshire, UK), which employs the technique of surface plasmon resonance to monitor the interaction of biomolecules in real time. Binding of analyte (mobile phase) to immobilised ligand was performed in $10 \mathrm{mM}$ Hepes, pH 7·4, $150 \mathrm{mM}$ NaCl, $3 \mathrm{mM}$ EDTA, 0.005\% surfactant P20 (HBS-EP-filtered -0.22um- and degassed). All binding reactions were examined at $25^{\circ} \mathrm{C}$.

\section{Equilibrium analysis of heparin-IGFBP interactions}

Streptavidin coated biosensor chips were obtained from BiaCore and were pre-treated in situ with $3 \times 5 \mu \mathrm{l}$ injections of $50 \mathrm{mM} \mathrm{NaOH}, 1 \mathrm{M} \mathrm{NaCl}$ to remove contaminants. Biotinylated-albumin (control flow cell) or biotinylated-albumin-heparin (test flow cell) were then 
immobilised by injection across the streptavidin surface from a $10 \mu \mathrm{g} / \mathrm{ml}$ solution in HBS-EP buffer. The substitution density of biotinylated ligand was controlled by the length of injection (0-2 min). We manufactured biosensor chips which contained 75, 184, 279 and 548 resonance units (RUs) of immobilised biotin-albuminheparin and equivalent substitution levels in control flow cells of biotinylated-albumin. Binding of analyte to biotinylated-albumin conjugate in the control flow cell was subtracted from binding to biotinylated-albuminheparin conjugate in the test flow cell. In addition, the zero analyte sensorgram was used as an additional control and subtracted from each sensorgram. As the stoichiometry of heparin-BP complexes are unknown, the $\mathrm{K}_{\mathrm{D}}$ value for heparin binding to IGFBP-3 and -5 was determined by the analysis of equilibrium binding levels achieved at ten different concentrations of ligand in HBS-EP buffer (Fig. la and b). For IGFBP-3 these were $0,0 \cdot 2,0 \cdot 39,0 \cdot 78,1 \cdot 56,3 \cdot 12,6 \cdot 25,12 \cdot 5,25$ and $50 \mathrm{nM}$ and for IGFBP-5, 0, 1·56, 3.12, 6.25, 12.5, 25, 50, 100, 200 and $400 \mathrm{nM}$. For both IGFBPs duplicate injections were performed. Visual inspection of sensorgrams indicated that equilibrium binding had been achieved at each analyte concentration. Software provided by the BiaCore 3000 was used to construct a graph of analyte concentration $\mathrm{v}$ Req (where Req is the equilibrium response achieved at each concentration of analyte) and $\mathrm{K}_{\mathrm{D}}$ was derived from this plot as analyte concentration at 0.5 Rmax. In these experiments, designed to obtain equilibrium constants for heparinIGFBP-3/5 interaction, an injection time of $12.5 \mathrm{~min}$ during the association phase was used and the complex was allowed to dissociate in analyte free buffer for $10 \mathrm{~min}$. The flow rate for these experiments was $20 \mu \mathrm{l} / \mathrm{min}$ and regeneration of bioactive chip surface was achieved with $2 \times 60$ s pulses of $100 \mathrm{mM} \mathrm{HCl}, 2 \mathrm{M}$ $\mathrm{NaCl}(30 \mu \mathrm{l} / \mathrm{min})$. Under these conditions complete regeneration was achieved and heparin surfaces were active for up to 300 cycles of binding and regeneration. For equilibrium analysis, four different biosensor chips were used with heparin substitution densities as indicated above.

\section{Effect of IGF complexation on IGFBP-heparin interactions}

The effect of IGF-I and IGF-II pre-complexation with IGFBP-5 or IGFBP-3 and the subsequent effect of interaction of BP with heparin was examined qualitatively by incubating a fixed concentration of IGFBP-3 or -5 with seven different concentrations of IGF-I or -II (see legend to Fig. 2 for concentrations) overnight at $4{ }^{\circ} \mathrm{C}$ prior to injection of IGF-IGFBP complexes across heparin biosensor surfaces. The association phase of these analyses was $3 \mathrm{~min}$ and the dissociation $15 \mathrm{~min}$. Because of the unknown stoichiometry of the interaction between IGFBPs and heparin this data was not subject to a kinetic analysis. The effect of IGF-I on the $\mathrm{K}_{\mathrm{D}}$ value for heparin-IGFBP-5 interaction was examined under equilibrium conditions at a fixed concentration of IGF-I $(6 \cdot 25 \mathrm{nM})$ and varying concentrations of IGFBP-5 $(0-100 \mathrm{nM})$ as described for equilibrium binding studies (Fig. 1).

\section{Effect of heparin complexation on IGFBP-IGF interactions}

The effect of heparin pre-complexation on the interaction of IGFBP-3 or IGFBP-5 with IGF-I biosensor surfaces was examined by incubating IGFBP-3 or IGFBP-5 at six different concentrations $(0-50 \mathrm{nM})$ with $1 \mu \mathrm{g} / \mathrm{ml}$ heparin overnight at $4{ }^{\circ} \mathrm{C}$ prior to injection across IGF-I biosensor surfaces. The method for analysis of interaction of IGFBP with immobilised IGF-I has been described in detail previously (Shand et al. 2003). The association phase of this analysis was $3 \mathrm{~min}$ and the dissociation phase $15 \mathrm{~min}$. The stoichiometry of the interaction between IGF and IGFBPs is 1:1 and the data were analysed with the 1:1 Langmuir model provided in the BiaEvaluation 3.1 software package associated with the instrumentation. At least three different sensor chips were used in these experiments and the substitution level of IGF-I in each of these surfaces was $<200$ RUs, leading to Rmax values $<160$ RUs. In analysing this data we employed similar arguments used by Vorwerk $e t$ al. (2002) who investigated N- and C-terminal fragments of hIGFBP-3 binding to immobilised IGFs. The accuracy of reported Rmax values was used to assess the appropriateness of kinetic fits of the data and if the value was deemed appropriate then data were analysed globally. Similarly, refractive index (RI) changes during the beginning of the association and dissociation phases were monitored closely and if fits of RI were inappropriate (i.e. did not correspond with changes in RI observed on the sensorgrams) then data was re-analysed using RI values estimated visually from the sensorgrams. As previously, in experiments using immobilised IGFs, we observed little mass transport limitation to reaction rates (Shand et al. 2003). The effect of heparin pre-incubated with IGFBP-3 and -5 on both $\mathrm{K}_{\mathrm{D}}$ (derived as a ratio of the rate constants $\left(\mathrm{K}_{\mathrm{d}} / \mathrm{K}_{\mathrm{a}}\right)$ ) and the Rmax value for IGF-I/IGFBP binding was monitored. The accuracy of fitted kinetic data was evidenced by chi-squared values \pm 5 .

\section{Displacement studies and ternary complex formation}

To examine directly the effect of IGF on the dissociation phase of the heparin-IGFBP interaction, IGFBP-3 or IGFBP-5 (both $25 \mathrm{nM}$ ) were allowed to bind to equilibrium during a 5 min injection phase over a heparin biosensor surface. After approximately $1 \mathrm{~min}$ of the dissociation phase, IGF-I (133 nM in HBS-EP buffer) was introduced and the rate of dissociation of 
(a)

RU

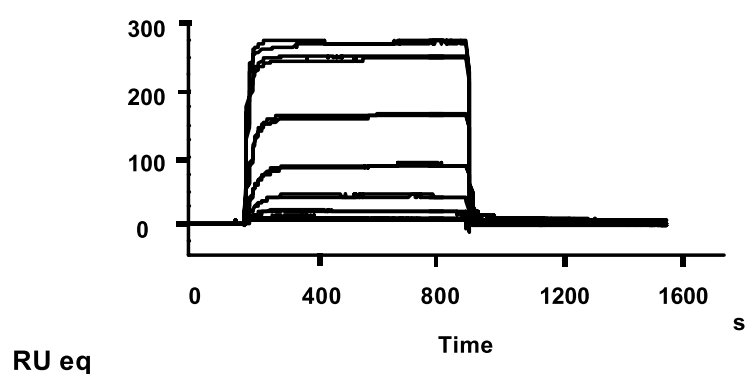

RU eq

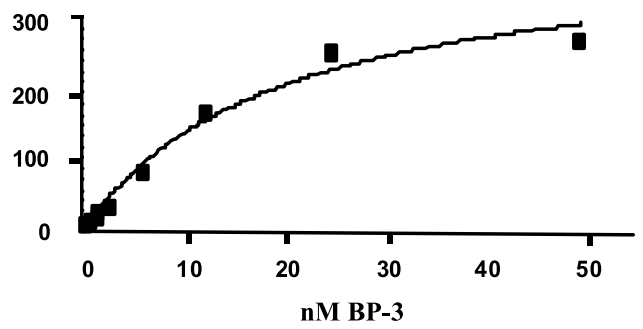

(b)

RU

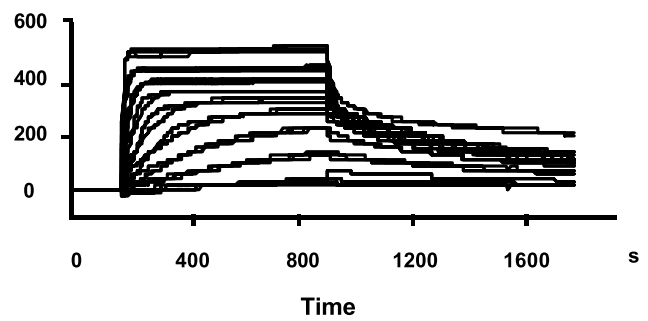

RU eq

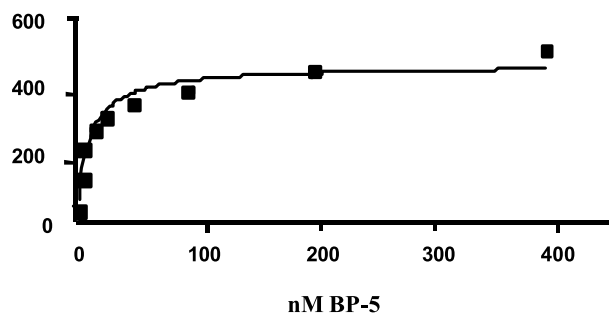

(c)

RU

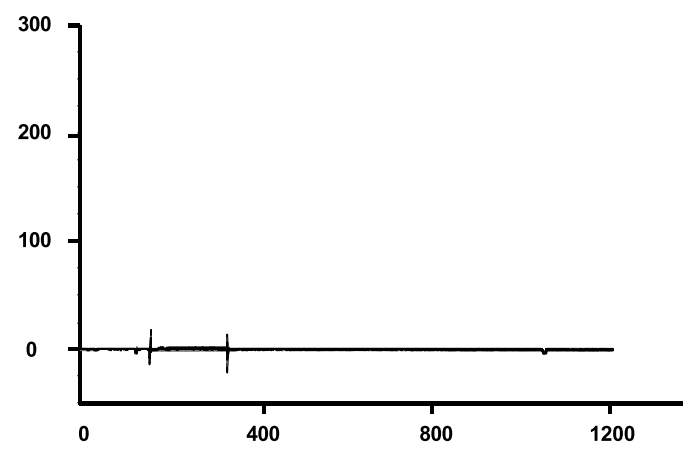

Time (s)
IGFBP-heparin complexes was compared with the dissociation seen in buffer alone. In similar experiments, IGFBP-3 or IGFBP-5 (both $25 \mathrm{nM}$ ) were allowed to bind during a 3 min injection over an IGF-I biosensor surface and the effect of the introduction of 10 or $100 \mu \mathrm{g} / \mathrm{ml}$ heparin solution (in HBS-EP buffer) on the rate of IGF-IGFBP dissociation was examined. In addition to the kinetics of the dissociation of binary complexes, sensorgrams were inspected for any increase in RU signal following introduction of the third component of the IGF-IGFBP-heparin complex (in both experimental configurations) as indicative of potential tripartite complex formation.

\section{Heparin ligand blot}

The method of blotting IGFBPs with a biotinylatedalbumin-heparin conjugate has been described previously (Song et al. 2000). Briefly, $250 \mathrm{ng}$ of mIGFBP-2, mIGFBP-3 or mIGFBP-5 were subject to non-reducing SDS-PAGE gel electrophoresis and blotted onto nitrocellulose. Hybridisation with the biotinylatedalbumin-heparin conjugate $(1 \mu \mathrm{g} / \mathrm{ml})$ was done in the presence or absence of $10 \mu \mathrm{g} / \mathrm{ml}$ IGF-I. IGFBP-2 does not bind heparin (Arai et al. 1996) and was used as a control in these experiments.

\section{Cell culture}

The undifferentiated mouse mammary epithelial cell line HC11 (Ball et al. 1988) was grown to confluence as described previously (Phillips et al. 2003). At confluence, cell monolayers were washed (x2) in Hanks Balanced Salt Solution (HBSS), then incubated for $2 \mathrm{~h}$ at $4{ }^{\circ} \mathrm{C}$ with $100 \mu \mathrm{l}$ of serum free medium (SFM) containing $1 \mu \mathrm{g} / \mathrm{ml} \mathrm{IGF}$, IGF-II, insulin or growth hormone $(\mathrm{GH})$. Following incubation, SFM was removed, centrifuged briefly and analysed for IGFBP-5 protein by Western blotting (Phillips et al. 2003).

Figure 1 Equilibrium binding analysis of IGFBP-3 (a) IGFBP-5 (b) or IGFBP-2 (c) binding to immobilised heparin biosensor surface. IGFBP-3 (0-50 nM), IGFBP-5 (0-400 nM) and IGFBP-2 (0-50 nM) were analysed at nine doubling concentrations (plus zero control) and injected in duplicate. The association phase of the binding curve was $12.5 \mathrm{~min}$ at a flow rate of $20 \mu \mathrm{l} / \mathrm{min}$ and complexes were dissociated for $10 \mathrm{~min}$ by switching to analyte free buffer. $\mathrm{K}_{\mathrm{D}}$ values were obtained from a plot of Req (RU value at equilibrium for each analyte concentration) $v$ analyte concentration. IGFBP-heparin interactions were analysed on biosensor chips derivatised with four different levels of immobilised heparin $(75,184,279$ and 548 RUs). Shown are representative data obtained with 184 RUs of immobilised heparin (IGFBP-3) and 279 RUs of immobilised heparin (IGFBP-5 and IGFBP-2). For further details see Materials and methods. 

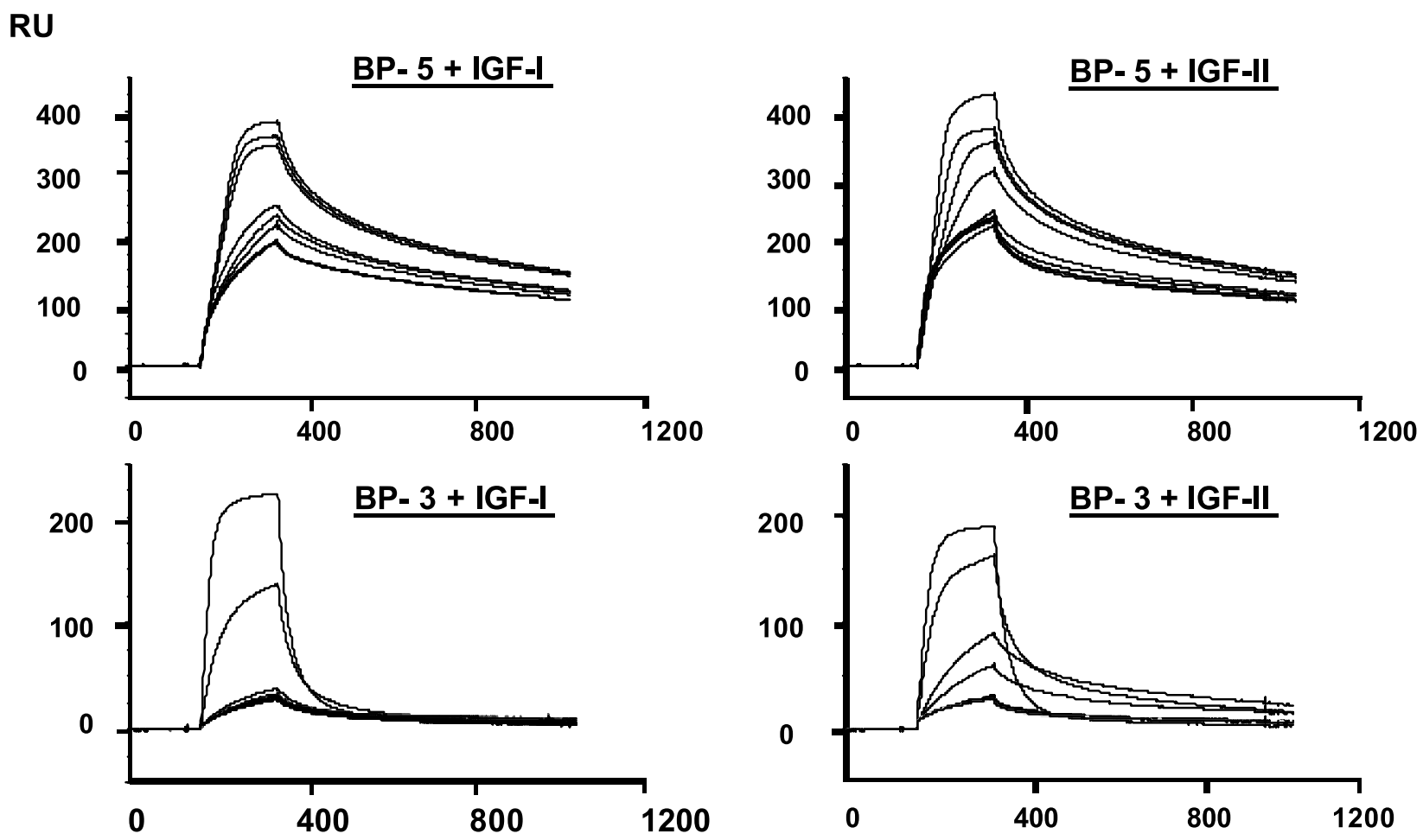

Figure 2 Effects of pre-incubation of IGFBP-3 and -5 with IGF-I or IGF-II on subsequent interaction with heparin biosensor surface. IGFBP-3 or IGFBP-5 (both $12.5 \mathrm{nM}$ ) were pre-incubated overnight at $4{ }^{\circ} \mathrm{C}$ with $0,6 \cdot 25,12.5,25,50,100,200$ and $400 \mathrm{nM}$ IGF-I or IGF-II in $300 \mu \mathrm{l}$ of HBS-EP buffer. For IGFBP-3 the concentration range of co-incubated IGF-I and IGF-II was 0-100 nM. Subsequently, IGF-IGFBP complexes were injected (in duplicate) across an immobilised heparin biosensor surface. For purposes of clarity only one sensorgram is shown for each co-incubated IGF concentration. Association was for 3 min and dissociation in analyte free buffer for $15 \mathrm{~min}$. This experiment was replicated on biosensor chips containing three different levels of immobilised heparin and similar results were obtained in each instance. Shown are representative data obtained with 279 RUs of immobilised heparin. For further details see Materials and methods.

\section{Results}

In Fig. la and b we present the results of a biosensor analysis designed to determine the equilibrium affinity constant for the interaction of IGFBP-3 and -5 with immobilised heparin. Binding reactions were allowed to achieve equilibrium over a $12.5 \mathrm{~min}$ injection period as described in Materials and methods and visual inspection of the upper graphs in Fig. la and b clearly indicate that a steady state level of binding was achieved. Under these circumstances a plot of Req (binding response at equilibrium) vs analyte concentration allows estimation of $\mathrm{K}_{\mathrm{D}}$ (as concentration of analyte at $1 / 2$ Rmax) for heparin interaction with BP. Equilibrium binding analysis was performed on biosensor surfaces containing four different levels of heparin substitution (see Materials and methods). Using these surfaces, values for $\mathrm{K}_{\mathrm{D}}$ were found to be $7 \cdot 22 \pm 2 \cdot 22$ and $22 \cdot 4 \pm$ $3 \cdot 48 \mathrm{nM}$ for IGFBP-5 and IGFBP-3 respectively (mean \pm s.E.; $n=4$ in both instances). As a control in our experiments we examined the interaction of mIGFBP-2 with heparin biosensor surfaces. Consistent with observations by other groups, using different methodologies (Arai et al. 1996), we found no interaction between IGFBP-2 and the heparin surface (Fig. 1c).

We next wished to examine whether precomplexation of IGFBP-3 or IGFBP-5 with cognate ligand (IGF-I or -II) had any effect on the subsequent interaction of either of the IGFBPs with heparin biosensor surfaces. In Fig. 2 fixed concentrations of either IGFBP-3 or IGFBP-5 $(12.5 \mathrm{nM})$ were incubated with varying concentrations of IGF-I or IGF-II (see figure legends for details) overnight at $4{ }^{\circ} \mathrm{C}$ and the binding of the IGFBP-IGF complex to heparin surfaces was subsequently examined. It is clear from Fig. 2 that both IGF-I and IGF-II inhibit the interaction between IGFBP-3 and -5 and heparin biosensor surfaces. It is important to note that under these conditions, neither IGF-I nor IGF-II themselves bind to heparin surfaces. Confirmation of the inhibitory effect of IGF engagement of IGFBP-3 and -5 on the subsequent binding of these IGFBPs to heparin was obtained using the technique of heparin ligand blotting as described in Fig. 3. We have previously used this methodology to investigate the 
$\mathrm{Mr}$
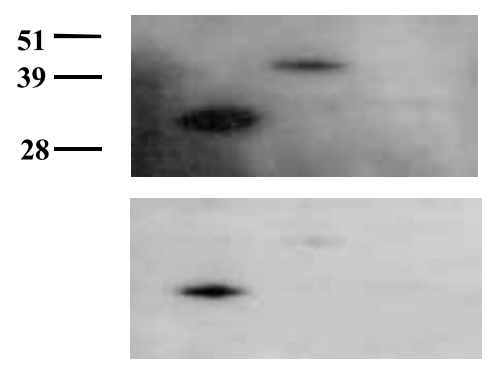

$\begin{array}{llll}\text { IGFBP } & 5 & 3 & 2\end{array}$

Figure 3 Heparin ligand blot. Commercial preparations of mouse IGFBP-2, -3 and -5 (250 ng) were run on non-reducing SDS gels, transferred to nitrocellulose and blotted with biotinylated-albumin-heparin as described in Materials and methods. Blots were hybridised in the absence (-IGF-I; upper panel) or presence (+IGF-I; lower panel) of $10 \mu \mathrm{g} / \mathrm{ml}$ IGF-I. IGFBP-2 is included as a non-heparin binding control. This experiment was repeated twice with similar results in each case.

heparin binding properties of wild type (wt) IGFBP-5 and various IGFBP-5 mutants (Song et al. 2000). When IGFBP-5 or IGFBP-3 are loaded at $250 \mathrm{ng}$, blotted onto nitrocellulose then hybridised with the biotinylatedalbumin-heparin conjugate, IGFBP-3 and IGFBP-5 show a clear reactivity (upper panel Fig. 3). As a control, IGFBP-2, which has no heparin binding activity, is not detected by this method. If hybridisation of the heparin conjugate is performed in the presence of $10 \mu \mathrm{g} / \mathrm{ml}$ unlabelled IGF-I, then the reactivity against IGFBP-5 is greatly decreased and the reactivity against IGFBP-3 is almost completely inhibited (lower panel Fig. 3). Importantly, this data confirms in a qualitative sense the results of the biosensor analysis described above. Also, under the equilibrium experimental conditions described in Fig. 1, incubation of a fixed concentration of IGF-I $(6 \cdot 25 \mathrm{nM})$ with a range of IGFBP-5 concentrations $(0-100 \mathrm{nM})$ indicated that IGF-I increased the $\mathrm{K}_{\mathrm{D}}$ for heparin-IGFBP-5 interactions approximately 5-fold (-7.2 vs $39 \cdot 4 \mathrm{nM}$; data not shown). In Fig. 2, a residual level of IGFBP binding to heparin surfaces was evident (especially for IGFBP-5) even at concentrations of IGF as high as $1 \mu \mathrm{M}$ (molar ratio of IGF:IGFBP $=80: 1$ ). We believe that this may reflect the affinity differences that IGFBP-3 and IGFBP-5 display towards heparin and IGF-I (see Discussion).

To examine in more detail the molecular interactions in the heparin-IGFBP-IGF axis, we performed biosensor experiments in a different experimental configuration. In this instance, varying concentrations of IGFBP-3 or -5 (see Materials and methods and Fig. 4 legend) were incubated in the absence or presence of heparin $(1 \mu \mathrm{g} / \mathrm{ml})$ and the effects of heparin pre-incubation on the kinetics of the interaction between IGFBP-3/5 and immobilised IGF-I were examined. As the interaction between IGF and IGFBPs occurs at a stoichiometry of $1: 1$ and is fully reversible, this interaction can be analysed kinetically to obtain association $\left(\mathrm{K}_{\mathrm{a}}\right)$ and dissociation $\left(\mathrm{K}_{\mathrm{d}}\right)$ rate constants and thus derive the equilibrium constant $\mathrm{K}_{\mathrm{D}}$ as $\mathrm{K}_{\mathrm{d}} / \mathrm{K}_{\mathrm{a}}$ and as such the effect of heparin pre-incubation on these parameters can be investigated. Analysis of the curves using BiaEvaluation software indicated that heparin increased the $\mathrm{K}_{\mathrm{D}}$ for IGF-I-IGFBP-3 interaction by approximately two-fold $0 \cdot 132 \pm 0 \cdot 017 \mathrm{nM} \quad$ vs $0.233 \pm 0 \cdot 062 \mathrm{nM} \quad(n=4 \pm$ S.E.; $P<0 \cdot 05)$. A visual inspection of Fig. 4 indicates that the increased $\mathrm{K}_{\mathrm{D}}$ value arises largely due to a decrease in the association rate constant for the interaction between IGFBP-3 and immobilised IGF-I, and quantitative kinetic analysis of rate constants confirms this. Association rate $\left(\mathrm{K}_{\mathrm{a}}\right)$ values in the absence and presence of heparin are $1.98 \pm 0.18 \mathrm{vs} 0.73 \pm 0.18\left(\mathrm{M} / \mathrm{s} \times 10^{6}\right)$ mean \pm S.E.; $n=4$. Corresponding $\mathrm{K}_{\mathrm{d}}$ values are $3 \cdot 47 \pm 0 \cdot 70$ vs $4 \cdot 29 \pm 2 \cdot 24\left(\times 10^{-3} / \mathrm{s}\right)$ mean \pm S.E. $n=4$. In duplicate experiments with IGFBP-5 in the presence or absence of $1 \mu \mathrm{g} / \mathrm{ml}$ heparin, $\mathrm{K}_{\mathrm{D}}$ for the IGF-IIGFBP-5 interaction was also increased by preincubation with heparin. In this instance however there appeared to be an almost 16 -fold increase in $\mathrm{K}_{\mathrm{D}}$ values. In duplicate experiments $\mathrm{K}_{\mathrm{D}}=0 \cdot 16$ and $0.23 \mathrm{nM}$ in the absence of heparin, and 3.47 and $2.87 \mathrm{nM}$ after pre-incubation with $1 \mu \mathrm{g} / \mathrm{ml}$ heparin. Kinetic analysis of the data indicated once again that increases in the equilibrium constant for interaction were largely due to a decrease in association rate following heparin incubation and this is confirmed by visual inspection of the sensorgrams in Fig. 4.

As a control we also examined the kinetics of interaction of IGFBP-2 with immobilised IGF-I and the effect of pre-incubation of IGFBP-2 with heparin on the kinetics of this interaction. Consistent with our earlier observations that IGFBP-2 does not interact with a heparin biosensor surface, pre-incubation of IGFBP-2 with heparin had no effect on the $\mathrm{K}_{\mathrm{D}}$ of interaction between IGFBP-2 and immobilised IGF-I (data not shown).

These results suggested that the IGFs and heparin may compete for the same or overlapping binding sites on IGFBP-3 and -5. It is possible however that IGF and heparin could bind to distinct sites on the IGFBP molecule and that the binding of one ligand could decrease the affinity of IGFBP for the second ligand through an allosteric conformational change in the IGFBP molecule. To address this question, we used the biosensor in an attempt to build a tri-partite molecular complex containing IGF, IGFBP and heparin. We have previously used this approach in a biosensor based epitope mapping strategy (Beattie et al. 1999) and, in the context of the IGF axis, such an approach has been used to identify two different fragments of bovine IGFBP-2 binding simultaneously to the IGF-II molecule 
RU
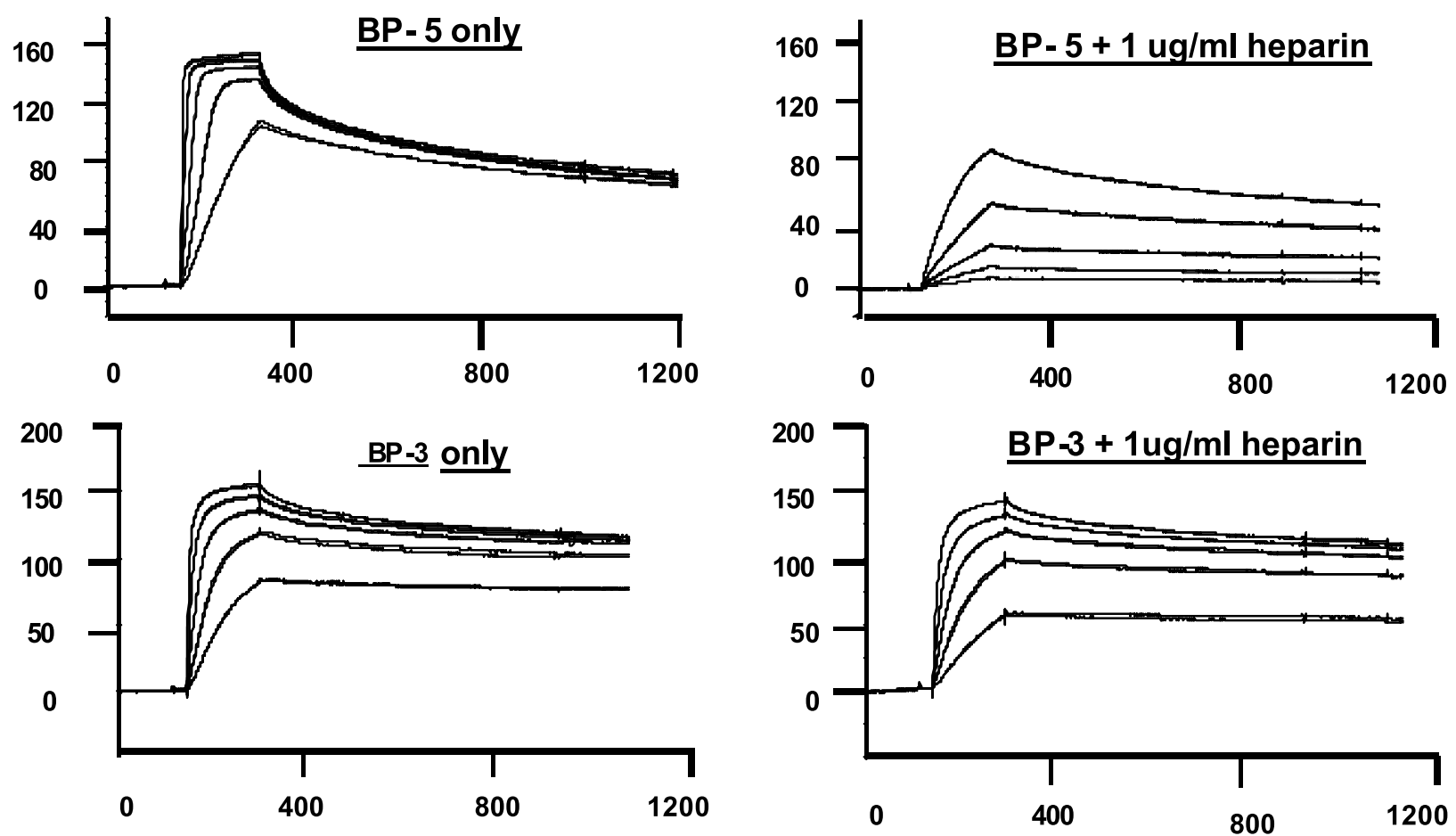

Time (s)

Figure 4 Effect of pre-incubation of IGFBP-3 or IGFBP-5 with heparin on subsequent interaction with IGF-I biosensor surface. (a) IGFBP-5 ( 0, 3.12, 6.25, 12.5, 25 and $50 \mathrm{nM})$ and (b) IGFBP-3 $(0,1.56,3 \cdot 12,6 \cdot 25,12.5$ and $25 \mathrm{nM})$ were incubated overnight at $4{ }^{\circ} \mathrm{C}$ with 0 or $1 \mu \mathrm{g} / \mathrm{ml}$ of heparin in $300 \mu \mathrm{l}$ of HBS-EP buffer. Subsequently, heparin-IGFBP complexes were injected (in duplicate) across an immobilised IGF-I biosensor surface. Association was for 3 min and dissociation in analyte free buffer for 15 min. This experiment was repeated 4 times for IGFBP-3 and twice for IGFBP-5. The data shown were generated using a biosensor surface containing 100 RUs of immobilised IGF-I. For further details see Materials and methods.

(Carrick et al. 2001). Inspection of Fig. 5a indicates that when IGFBP-5 or -3 is bound to the heparin biosensor surface then the introduction of IGF-I (133 nM) does not lead to any increase in RU signal. Indeed introduction of IGF-I into the flow cell leads to a rapid dissociation of IGFBP-5 from the heparin surface and this dissociation is faster than that achieved in analyte free buffer alone (Fig. 5; upper panel). This suggests that IGF-I rapidly displaces IGFBP-5 from heparin in the biosensor flow cell. Interestingly, this effect was not observed with IGF-I when IGFBP-3 was pre-bound to the heparin surface (Fig. 5a; lower panel). In the case of both IGFBP-3 and -5, there was no evidence of any increase in RU signal following introduction of IGF-I into the flow cell. When IGFBP-5 or IGFBP-3 was pre-bound to the IGF-I biosensor surface, and heparin introduced (10 or $100 \mu \mathrm{g} / \mathrm{ml}$ ) only the higher concentration of heparin resulted in a small increase in the rate of dissociation of IGF-IGFBP-5 complexes (Fig. 5b). These results show no evidence for any increase in RU signal indicative of possible tri-partite complex formation between IGF-I, IGFBP and heparin. In order to examine whether IGFs could displace IGFBP-5 under cell culture conditions and thus confirm the biosensor data presented in Fig. 5a, we used the mammary epithelial cell line HC11. This cell line has been shown to secrete high levels of IGFBP-5 (Phillips et al. 2003) and also synthesises the ECM proteins laminin and tenascin (Chammas et al. 1994). IGFBP-5 has in turn been reported to bind laminin (Jones et al. 1993) and we considered, therefore, that HC11 cells would be a good model in which to examine the ability of IGFs to displace IGFBP-5 from ECM/cellular binding sites. Figure 6 shows the results of a representative experiment in which washed monolayers of HCll cells were incubated with SFM or SFM containing $1 \mu \mathrm{g} / \mathrm{ml}$ IGF-I, IGF-II, insulin or GH for $2 \mathrm{~h}$ at $4{ }^{\circ} \mathrm{C}$ followed by analysis of SFM for the presence of released IGFBP-5. It is evident that incubation with IGF-I and IGF-II increases the level of IGFBP-5 released into conditioned medium above that in control 
(a)

\section{RU}
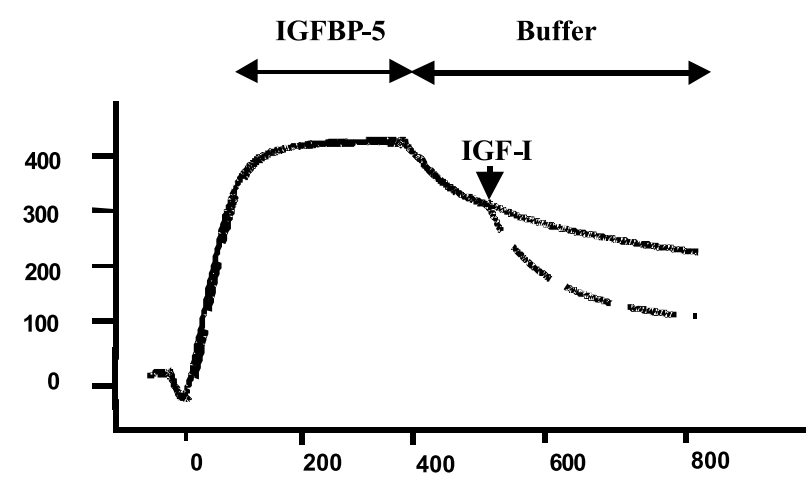

Time ( s )

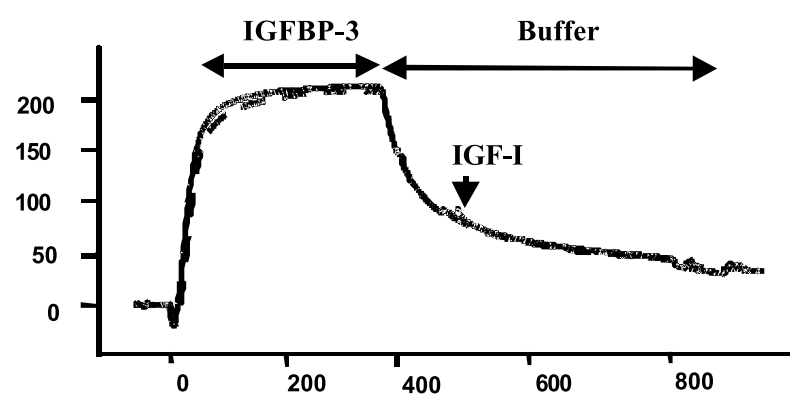

Time ( s )

(b)
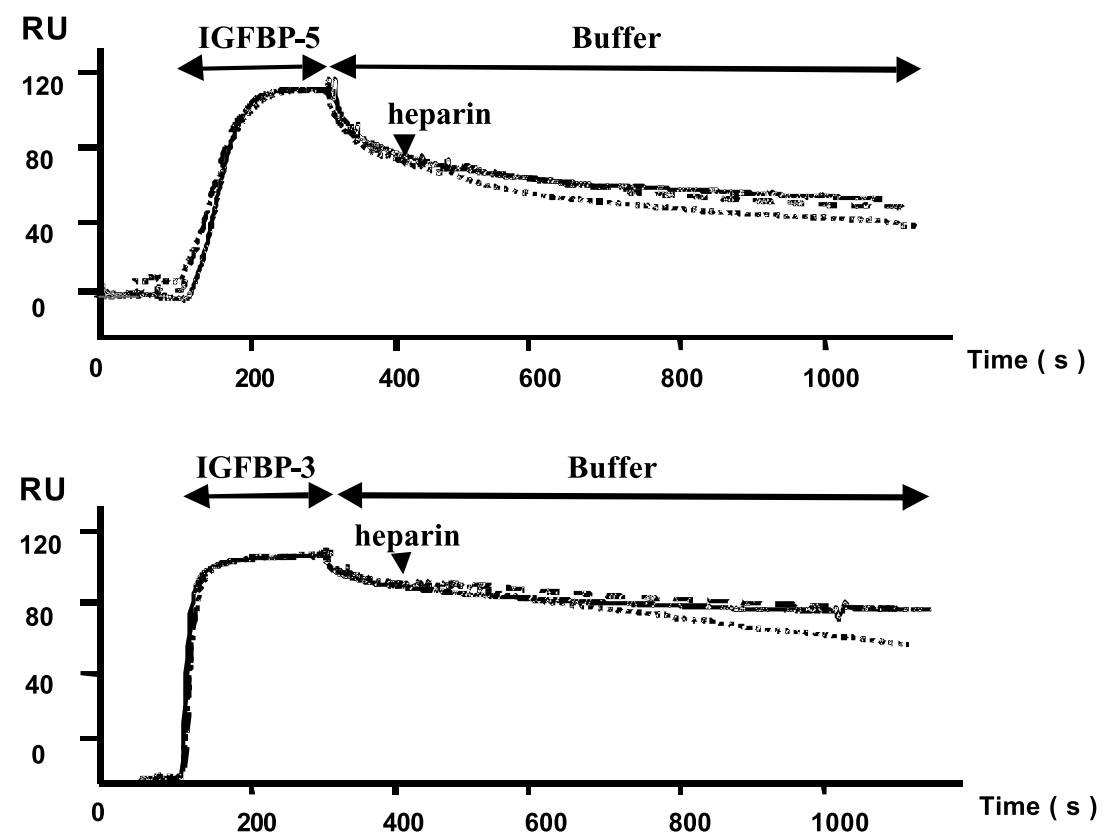

Figure 5 (a)Displacement of IGFBP-5 by IGF-I from a heparin biosensor surface. IGFBP-5 (50 nM upper panel) or IGFBP-3 ( $25 \mathrm{nM}$-lower panel) was injected across a heparin biosensor surface for $5 \mathrm{~min}$ at a flow rate of $30 \mu \mathrm{l} / \mathrm{min}$. During the dissociation phase, 133 nM IGF-I (arrow; dashed line) or buffer alone (solid line) was injected at the indicated time point and the dissociation phase was allowed to proceed for a further $10 \mathrm{~min}$. Sensorgrams showing the dissociation profile following IGF-I or buffer injection have been overlaid to highlight the effect of IGF-I on the dissociation of IGFBP-heparin complexes. (See Materials and methods for further details). (b) IGFBP-5 (25 nM; upper panel) or IGFBP-3 (25 nM-lower panel) was injected for 3 min across an IGF-I biosensor surface. During the dissociation phase heparin $(10 \mu \mathrm{g} / \mathrm{ml}$ (dashed line) or $100 \mu \mathrm{g} / \mathrm{ml}$ (dotted line) was injected at the indicated time point. Dissociation was allowed to proceed for another $10 \mathrm{~min}$ and the rate of dissociation of IGFBP-5 or IGFBP-3 from the IGF-I surface in the presence or absence (solid line) of heparin was monitored. Sensorgrams have been overlaid as described in (a). 


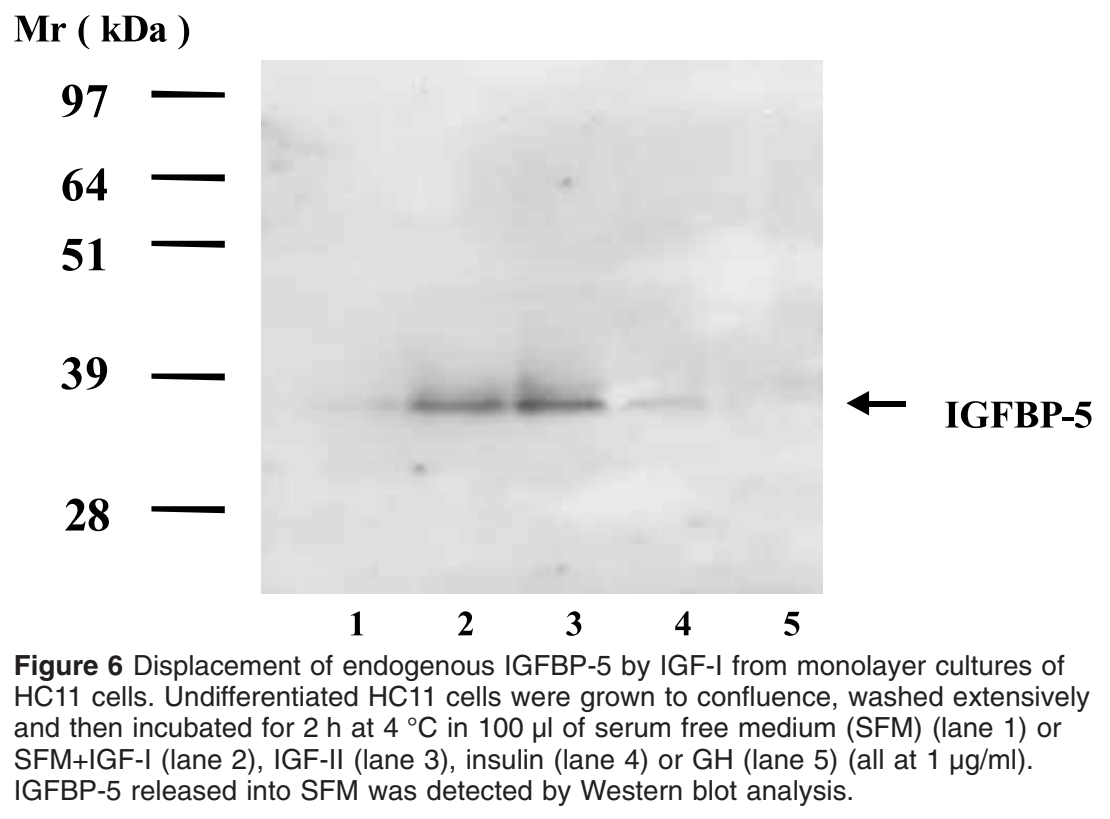

(SFM) samples. Insulin which has a much reduced affinity for IGFBPs releases very little IGFBP-5 into conditioned medium and $\mathrm{GH}$ which is used as a control in these experiments releases no IGFBP-5 into conditioned medium. These data suggest that IGFs are able to release IGFBP-5 from HC11 cell monolayers.

\section{Discussion}

The use of biosensor technology to examine the interaction between IGFs and IGFBPs has been previously reported for bovine IGFBP-2 (Hobba et al. 1998, Carrick et al. 2001) for human IGFBP-3 and different $\mathrm{N}$ - and C-terminal fragments of this protein (Heding et al. 1996, Galanis et al. 2001, Vorwerk et al. 2002), for human IGFBP-6 (Marinaro et al. 1999) and the entire series of human IGFBPs 1-6 (Wong et al. 1999). In addition, the interaction between IGFs and immobilised IGF-I receptor has been reported (Forbes et al. 2002). A major concern of biosensor studies has been the relationship between affinities reported using this technology (where one of the binding partners is effectively immobilised on a carboxy-dextran matrix) and that reported between the two proteins interacting freely in solution. For the IGF-IGFBP complex we, and others in the studies cited above, have found that affinities reported using biosensor are similar to those which have been determined previously by solution phase binding studies. We believe therefore that biosensor technology reports accurately on the affinities of interaction between this particular protein pair. In our experiments we used IGF-I as immobilised ligand with
IGFBP-3 or -5 as the mobile phase analyte. Although some studies have been performed in the reverse orientation with immobilised $\mathrm{BP}$ as ligand and IGFs present as mobile phase analyte (Heding et al. 1996, Marinaro et al. 1999) we found that IGFBP biosensor chips were less robust than IGF surfaces and thus did not lend themselves well to the repeated cycles of binding and regeneration which are required to obtain reliable and reproducible data. In addition the difference in $\mathrm{Mr}$ between IGF-I and IGFBP-3/5 allows for a much larger RU signal to be obtained when IGFBPs are used as analyte, allowing lower concentrations of analyte to be used and allowing better fits of kinetic data.

The use of heparin coated biosensor surfaces has also been previously reported to monitor the interaction of heparin with antithrombotic protein $\mathrm{G}$ (Friedrich et al. 2001) and with acidic and basic fibroblast growth factor (aFGF and bFGF; Mach et al. 1993, Kinsella et al. 1998). The unavailability of primary amine groups in heparin (and therefore the inability to couple this GAG using hetero-bifunctional linkers to activated carboxy-methyl surfaces) has led to the use of biotinylated derivatives together with streptavidin coated biosensor chips (Osmond et al. 2002). Our heparin biosensor surface used a biotinylated-albumin-heparin conjugate. This reagent contains heparin linked via reductive amination of the terminal reducing sugar to albumin via a hetero-bifunctional cross-linking reagent as is typical for protein-protein linkages, with conjugation of biotin to the albumin moiety via biotinamido-caproic acid (www.sigmaaldrich.com/suite7; Ishikawa et al. 1983, Sasaki et al. 1987). This type of chemical link allows access of IGFBPs to the full length of the GAG polymer 
and is reported to produce heparin biosensor surfaces with high binding capacity (Osmond et al. 2002).

The objective of the current study was to determine the nature of the interactions between IGF, IGFBP-3/5 and heparin. Previous studies had determined that heparin binding of IGFBP-5 lowered the affinity of this BP for IGF-I. However little is known about the nature of the potential IGF-IGFBP-heparin complexes which may exist particularly with respect to whether ternary complexes of IGF-IGFBP-heparin can exist or whether binding of IGF and heparin to IGFBP-5 is mutually exclusive. Under these latter conditions, it is unlikely that such ternary complexes would exist. In support of this, previous data from our laboratory, using sitedirected mutagenesis, suggested that there may be overlap in the binding sites for IGF and heparin on the IGFBP-5 protein and we therefore wished to test this hypothesis further. For this reason we conducted a series of biosensor based experiments to examine the binding relationships in this complex. Initially we determined the affinity of both IGFBP-3 and IGFBP-5 for heparin. As indicated, equilibrium analysis of this binding using biosensor gave values of $22 \cdot 4$ and $7 \cdot 22 \mathrm{nM}$ for IGFBP-3 and IGFBP-5 respectively. This binding is therefore around 10-30 fold weaker than the binding of IGFBPs with IGF ligands. It has been argued that the immobilisation of ligand on the surface of a biosensor chip may compromise the binding of ligand to analyte. In the case of heparin we believe that the immobilisation of this GAG may in fact represent a close approximation of the situation in vivo where heparan sulphate chains are closely associated with cellular membranes and other extracellular polymers. Although the stoichiometry of interaction between the IGFBPs and heparin is unknown, an approximate stoichiometric ratio can be achieved using the Rmax values obtained during the equilibrium binding experiments between IGFBPs and immobilised heparin. For example, for the analysis of IGFBP-5 binding on the heparin biosensor chip substituted to a level of 184 RUs (RU ligand), the Rmax value obtained is 290 RUs (RU analyte). The stoichiometry of interaction $(\mathrm{s})$ is then defined as:

$$
\mathrm{S}=\frac{\mathrm{RU}(\text { analyte }) \times \mathrm{Mr} \text { (ligand) }}{\mathrm{RU}(\text { ligand }) \times \mathrm{Mr} \text { (analyte })}
$$

(this assumes no steric hindrance or compromised binding due to method of ligand immobilisation).

For IGFBP-5 (analyte), $\mathrm{Mr}=28.5 \mathrm{kDa}$ and for biotinylated-albumin-heparin conjugate (ligand) $\mathrm{Mr}=$ $118 \mathrm{kDa}$, then stoichiometry of interaction is $6 \cdot 5: 1$ (IGFBP-5:heparin). An equilibrium binding analysis of IGFBP-5 on four biosensor chips containing biotinylated-albumin-heparin substituted to four different levels gave an average stoichiometry of $5 \cdot 95 \pm 1 \cdot 6$ and for IGFBP-3, 6.33 $\pm 1 \cdot 37$ (mean \pm S.E.). For the biotinylated-albumin-heparin conjugate the mole fraction of heparin is $42.8 \%(50.5 \mathrm{kDa} \mathrm{Mr}$ ) (Sigma) and with three heparin chains per albumin molecule the average $\mathrm{Mr}$ of a chain is $16 \cdot 8 \mathrm{kDa}$. Assuming an $\mathrm{Mr}$ for the constituent disaccharide $\mathrm{N}$-acetyl glucosamine-iduronic acid of $354 \mathrm{Da}$ then this approximates to 47 repeating disaccharide units each containing two bound IGFBP proteins. In comparison, Mach et al. (1993) investigating the interaction of aFGF $(15.8 \mathrm{kDa})$ with $16 \mathrm{kDa}$ heparin used a similar biosensor based analysis to report a stoichiometry of 10:1 (aFGF:heparin). Interestingly, an analysis of this same interaction using the technique of dynamic light scattering reported a stoichiometry of 15:1 or $50 \%$ greater than that determined by biosensor. Clearly the stoichiometry of IGFBP-5 and heparin interaction requires to be confirmed by an alternative methodology. One of the principle aims of the current study was to investigate whether ternary complexes of IGF-IGFBP-heparin could exist. The weight of the data in our study suggests that this is not the case and that binding of IGF and heparin to IGFBP-3/5 is mutually exclusive. Firstly, pre-complexation and overnight incubation of IGF-I or IGFII (but not insulin) with IGFBP-3 or IGFBP-5 inhibits the subsequent interaction of $\mathrm{BP}$ with heparin biosensor surfaces (Fig. 2). A visual inspection of the sensorgrams in these experiments shows qualitatively that the rate of association of IGFBP-IGF complexes with the heparin biosensor surface is decreased as concentrations of IGF are increased. For IGFBP-5, we found that even at high molar IGF:IGFBP-5 ratios (80:1) there was still some residual binding of IGFBP- 5 to the heparin surface and that this was confirmed by the heparin blotting data presented in Fig. 3. In repeated experiments we found an almost complete inhibition of binding to heparin at high molar IGF:IGFBP-3 ratios but in the case of IGFBP-5 we found some residual heparin binding even at high concentrations of IGFs. We believe that this data reflects a combination of a higher affinity of IGFBP- 5 for heparin combined with a lower affinity for IGF-I and IGF-II when compared with IGFBP-3 (Wong et al. 1999). This is clearly an area which requires further investigation.

In an attempt to address some of the kinetic aspects of the molecular recognition events in the IGF-IGFBPheparin axis, we focussed on the effect of heparin pre-incubation with both IGFBPs on the interaction between IGFBP-3 or -5 and immobilised IGF-I. This latter interaction is well characterised in terms of biosensor studies by ourselves (Song et al. 2000, Shand et al. 2003) and other groups (Marinaro et al. 1999, Wong et al. 1999, Carrick et al. 2001) and conforms to a classical 1:1 stoichiometric, fully reversible interaction whose kinetics can be described by the Langmuir binding isotherm software supplied by the BiaCore 3000 instrumentation. As such this particular experimental 
design allows for a more straightforward interpretation of the kinetics of IGF-IGFBP interactions and the effects of heparin thereon. Our data (Fig. 4) indicate that heparin pre-incubation with IGFBP-3 or IGFBP-5 increases the KD of interaction between IGF-I and IGFBPs (2- and 16-fold for IGFBP-3 and IGFBP-5 respectively). Previous reports on the effect of heparin on the affinity of interaction between IGFBP-5 and IGF-I used a Scatchard analysis of data derived from the incubation of ${ }^{125}$ I-IGF-I with purified BP in the absence or presence of $10 \mu \mathrm{g} / \mathrm{ml}$ heparin and reported a 17 -fold decrease in affinity for IGFBP-5 and a two-fold decrease in affinity for IGFBP-3 pre-bound to heparin (Arai et al. 1994b), agreeing very closely with the data reported in the current study. No values for equilibrium constants were reported. These findings were essentially confirmed when the same group demonstrated that interaction of IGFBP-5 with ECM derived from human foetal fibroblasts, or with collagen, resulted in an approximately 10-fold drop in affinity between IGFBP-5 and IGF-I $\left(\mathrm{K}_{\mathrm{A}} \sim 10^{10} \mathrm{M}\right.$ vs $10^{9} \mathrm{M}$; Jones et al. 1993). The results of our experiments still did not address the question of possible ternary complex formation between IGF-IGFBP-heparin. To obtain further evidence on the nature of the IGF-IGFBP-heparin complexes we once again undertook biosensor experiments. Using either IGF or heparin biosensor surfaces, we were unable to build ternary complexes containing all three components (Fig. 5a and b). In fact for IGFBP-5, following formation of the heparin-IGFBP binary complex, subsequent addition of IGF-I resulted in the rapid dissociation of the binary complex (Fig. 5a; upper panel) with little evidence of even a transient increase in RU signal which would be associated with ternary complex formation. For IGFBP-3, we did not observe any increase in the rate of dissociation of the heparin BP complex. This may be due to the already very fast dissociation rate of IGFBP-3 from heparin (see Fig. 1a) such that IGF-I addition has little effect. When this experiment is performed in a different format, with IGFBP-3 or -5 pre-bound to IGF-I biosensor surfaces, heparin is able to increase the rate of dissociation of IGFBP-5 and IGFBP-3 complexes to a small extent at the relatively high concentration of $100 \mu \mathrm{g} / \mathrm{ml}$ (Fig. 5b).

Several of the observations reported in the current study may have important biological implications. For example, although IGFBP-3 and IGFBP-5 show similar $\mathrm{K}_{\mathrm{D}}$ values for binding heparin, it is clear that IGFBP-3 has a faster $\mathrm{K}_{\mathrm{a}}$ and also a faster $\mathrm{K}_{\mathrm{d}}$ than IGFBP-5, indicating that the heparin-IGFBP-3 complex may be a much more dynamic or transient complex than the IGFBP-5 complex, and the more stable complex formed between heparin and IGFBP-5 may explain the protection from proteolysis which GAG engagement confers on this protein (Arai et al. 1994a). However, it is also the case that endogenous or exogenous IGFBP-5 added to ECM preparations derived from the human foetal fibroblast cell line GM10 diffuses from the ECM (Jones et al. 1993), and it would appear therefore that the ECM-IGFBP-5 interaction may also be dynamic. Contrary to our conclusions it has been suggested that the heparin and IGF binding sites in IGFBP-5 are distinct, and that binding of IGFBP-5 to extracellular matrix may cause a conformational change in IGFBP-5, lowering the $\mathrm{K}_{\mathrm{D}}$ for interaction between IGFs and IGFBP-5, thus suggesting that heparin and other extracellular GAGs may act as a 'low affinity sink' for IGF peptide, facilitating the interaction between IGFs and their receptors on the cell surface. In support of this hypothesis it was shown that a short peptide from the heparin binding domain of IGFBP-5, whilst inhibiting the interaction between heparin and IGFBP-5, did not inhibit the interaction between IGF-I and IGFBP-5. It must be questioned however whether such a short peptide would retain sufficient structure to form a high affinity IGF binding site. The data in the current manuscript may suggest an additional interpretation of the molecular relationships in the IGF-IGFBPheparin axis whereby heparin or heparan sulphate, and certain other GAGs, are occupied with unliganded IGFBP-3 and -5 and that free IGF in the local environment may displace IGFBP-3 and -5 from ECM as IGF-IGFBP complexes. Indeed it has been shown previously that addition of IGF-I to cultures of human fibroblasts will release IGFBP-3 into conditioned medium (Conover 1991, Martin et al. 1992). Although to our knowledge no equivalent data existed to demonstrate IGF-dependent release of IGFBP-5 in a cell culture model, we were able to demonstrate that IGF-I and -II could displace endogenous IGFBP-5 from monolayers of the mouse mammary epithelial cell line HC1 1 (Fig. 6). It is important to note that our data do not preclude the reverse scenario where defined EGM components are able to competitively disrupt the IGF-IGFBP interaction, effectively releasing IGFs and creating a protease protected pool of IGFBP-3 and IGFBP-5. Indeed in a recent review Schneider et al. (2002) described this possibility. Another important aspect to the biology of IGFBP-3 and -5 is the fact that these proteins are reported to interact with several other extracellular molecules and/or structures (see Introduction). As the region 201-218 of the IGFBP-3 and -5 has been implicated in these interactions this suggests that IGFs may have the potential to disrupt IGFBP binding to these proteins/structures and this may in turn have important biological consequences. In terms of the recognition characteristics in this molecular axis it is perhaps of special interest that the $85 \mathrm{kDa}$ glycoprotein ALS (Baxter 1988) is also believed to interact with IGFBP-3 and -5 via the 201-218 region (Hashimoto et al. 1997, Firth et al. 1998, Twigg et al. 1998). However it has been clearly demonstrated that prior engagement 
of IGF-I or IGF-II by BPs is required before IGFBP-3 or -5 can bind to ALS. Our data suggest that binding of a protein or GAG in the 201-218 region of IGFBP-5 may occlude subsequent IGF binding and this suggests that ALS may engage IGF-IGFBP-5 binary complexes at a site other than the 201-218 region. It is interesting that a recent report indicates that there is also a site in the central domain of IGFBP-5 which can bind to ALS (Twigg et al. 2000). It will be of interest to investigate whether this particular pattern of molecular contacts is present in vivo for IGF-IGFBP-5/3-ALS complexes.

In summary, the dynamics of the IGF-IGFBPheparin complex will be influenced by the affinities between the varying interacting molecules and the relative concentrations of each of the components in a defined micro-environment. In this particular case the lower affinity of the heparin-IGFBP interaction compared with the IGF-IGFBP interaction may be offset by higher concentrations of IGFBP binding sites in GAGs. It is also clear that the distribution of the various complexes will be influenced by the relative local abundance of IGFBP-3, IGFBP -5 and IGFs and that the actual molecular species present at the ECM surface will reflect these features.

\section{Acknowledgements}

This work was supported by the Scottish Executive Environment and Rural Affairs Department (SEERAD). $\mathrm{M} \mathrm{Sz}$ holds an EU-COST action post-doctoral research fellowship.

\section{References}

Allan GJ, Tonner E, Barber MC, Travers MT, Shand JH, Vernon RG, Kelly PA, Binart N \& Flint DJ 2002 Growth hormone, acting in part through the insulin-like growth factor axis, rescues developmental, but not metabolic, activity in the mammary gland of mice expressing a single allele of the prolactin receptor. Endocrinology $1434310-4319$.

Arai T, Arai A, Busby WH Jr \& Clemmons DR 1994a Glycosaminoglycans inhibit degradation of insulin-like growth factor-BP-5. Endocrinology 135 2358-2363.

Arai T, Parker A, Busby W Jr \& Clemmons DR $1994 b$ Heparin, heparan sulfate, and dermatan sulfate regulate formation of the insulin-like growth factor-I and insulin-like growth factor-BP complexes. Fournal of Biological Chemistry $26920388-20393$.

Arai T, Busby W Jr \& Clemmons DR 1996 Binding of insulin-like growth factor (IGF) I or II to IGF-BP-2 enables it to bind to heparin and extracellular matrix. Endocrinology 137 4571-4575.

Ball RK, Friis RR, Schoenenberger CA, Doppler W \& Groner B 1988 Prolactin regulation of beta-casein gene expression and of a cytosolic 120-kd protein in a cloned mouse mammary epithelial cell line. Embo fournal 7 2089-2095.

Bang P 1995 Serum proteolysis of IGFBP-3. Progress in Growth Factor Research 6 285-292.

Baxter RC 1988 Characterization of the acid-labile subunit of the growth hormone-dependent insulin-like growth factor BP complex. Fournal of Clinical Endocrinology and Metabolism 67 265-272.
Baxter RC 1990 Glycosaminoglycans inhibit formation of the $140 \mathrm{kDa}$ insulin-like growth factor-BP complex. Biochemical fournal $271773-777$.

Baxter RC \& Firth SM 1995 Modulation of human IGF BP-3 activity by structural modification. Progress in Growth Factor Research 6 215-222.

Beattie J, Bramani S, Secchi C \& Mockridge JM 1999 Binding and signalling properties of a growth hormone enhancing monoclonal antibody. Molecular and Cellular Biochemistry 198 61-67.

Campbell PG \& Andress DL 1997 Insulin-like growth factor (IGF)-BP-5-(201-218) region regulates hydroxyapatite and IGF-I binding. American Foumal of Physiology 273 E1005-E1013.

Carrick FE, Forbes BE \& Wallace JC 2001 BIAcore analysis of bovine insulin-like growth factor (IGF)-BP-2 identifies major IGF binding site determinants in both the amino- and carboxyl-terminal domains. Fournal of Biological Chemistry 276 27120-27128.

Chammas R, Taverna D, Gella N, Santos C \& Hynes NE 1994 Laminin and tenascin assembly and expression regulate HC11 mouse mammary cell differentiation. Fournal of Cell Science $\mathbf{1 0 7}$ 1031-1040.

Clemmons DR, Underwood LE, Chatelain PG \& Van Wyk JJ 1983 Liberation of immunoreactive somatomedin-C from its BPs by proteolytic enzymes and heparin. Fournal of Clinical Endocrinology and Metabolism 56 384-389.

Conover CA 1991 A unique receptor-independent mechanism by which insulin-like growth factor I regulates the availability of insulin-like growth factor BPs in normal and transformed human fibroblasts. Fournal of Clinical Investigation 88 1354-1361.

Donnelly MJ \& Holly JM 1996 The role of IGFBP-3 in the regulation of IGFBP-4 proteolysis. Fournal of Endocrinology 149 R1-R7.

Ferry RJ Jr, Katz LE, Grimberg A, Cohen P \& Weinzimer SA 1999 Cellular actions of insulin-like growth factor BPs. Hormone and Metabolic Research 31 192-202.

Firth SM \& Baxter RC 2002 Cellular actions of the insulin-like growth factor BPs. Endocrine Reviewes 23 824-854.

Firth SM, Ganeshprasad U \& Baxter RC 1998 Structural determinants of ligand and cell surface binding of insulin-like growth factor-BP-3. Fournal of Biological Chemistry 273 2631-2638.

Forbes BE, Hartfield PJ, McNeil KA, Surinya KH, Milner SJ, Cosgrove LJ \& Wallace JC 2002 Characteristics of binding of insulin-like growth factor (IGF)-I and IGF-II analogues to the type 1 IGF receptor determined by BIAcore analysis. European Fournal of Biochemistry 269 961-968.

Friedrich U, Blom AM, Dahlback B \& Villoutreix BO 2001 Structural and energetic characteristics of the heparin-binding site in antithrombotic protein C. Fournal of Biological Chemistry 276 24122-24128.

Galanis M, Firth SM, Bond J, Nathanielsz A, Kortt AA, Hudson PJ \& Baxter RC 2001 Ligand-binding characteristics of recombinant amino- and carboxyl-terminal fragments of human insulin-like growth factor-BP-3. Fournal of Endocrinology 169 123-133.

Hashimoto R, Ono M, Fujiwara H, Higashihashi N, Yoshida M, Enjoh-Kimura T \& Sakano K 1997 Binding sites and binding properties of binary and ternary complexes of insulin-like growth factor-II (IGF-II), IGF-BP-3, and acid-labile subunit. Foumal of Biological Chemistry 272 27936-27942.

Heding A, Gill R, Ogawa Y, De Meyts P \& Shymko RM 1996 Biosensor measurement of the binding of insulin-like growth factors I and II and their analogues to the insulin-like growth factor-BP-3. Journal of Biological Chemistry 271 13948-13952.

Hobba GD, Lothgren A, Holmberg E, Forbes BE, Francis GL \& Wallace JC 1998 Alanine screening mutagenesis establishes tyrosine 60 of bovine insulin-like growth factor BP-2 as a determinant of insulin-like growth factor binding. Fournal of Biological Chemistry 273 19691-19698. 
Hodgkinson SC, Napier JR, Spencer GS \& Bass JJ 1994 Glycosaminoglycan binding characteristics of the insulin-like growth factor-BPs. Fournal of Molecular Endocrinology 13 105-112.

Ishikawa E, Imagawa M, Hashida S, Yoshitake S, Hamaguchi Y \& Ueno T 1983 Enzyme-labeling of antibodies and their fragments for enzyme immunoassay and immunohistochemical staining. Fournal of Immunoassay 4 209-327.

Jones JI, Gockerman A, Busby WH Jr, Camacho-Hubner C \& Clemmons DR 1993 Extracellular matrix contains insulin-like growth factor BP-5: potentiation of the effects of IGF-I. Fournal of Cell Biology 121 679-687.

Kinsella L, Chen HL, Smith JA, Rudland PS \& Fernig DG 1998 Interactions of putative heparin-binding domains of basic fibroblast growth factor and its receptor, FGFR-1, with heparin using synthetic peptides. Glycoconjugate fournal 15 419-422.

Mach H, Volkin DB, Burke CJ, Middaugh CR, Linhardt RJ, Fromm JR, Loganathan D \& Mattsson L 1993 Nature of the interaction of heparin with acidic fibroblast growth factor. Biochemistry 32 5480-5489.

Marinaro JA, Jamieson GP, Hogarth PM \& Bach LA 1999 Differential dissociation kinetics explain the binding preference of insulin-like growth factor BP-6 for insulin-like growth factor-II over insulin-like growth factor-I. FEBS Letters 450 240-244.

Martin JL, Ballesteros M \& Baxter RC 1992 Insulin-like growth factor-I (IGF-I) and transforming growth factor-beta 1 release IGF-BP-3 from human fibroblasts by different mechanisms. Endocrinology 131 1703-1710.

Nam T, Moralez A \& Clemmons D 2002 Vitronectin binding to IGF BP-5 (IGFBP-5) alters IGFBP-5 modulation of IGF-I actions. Endocrinology 143 30-36.

Nam TJ, Busby W Jr \& Clemmons DR 1997 Insulin-like growth factor BP-5 binds to plasminogen activator inhibitor-I. Endocrinology 138 2972-2978.

Nam TJ, Busby WH Jr, Rees C \& Clemmons DR 2000 Thrombospondin and osteopontin bind to insulin-like growth factor (IGF)-BP-5 leading to an alteration in IGF-I-stimulated cell growth. Endocrinology 141 1100-1106.

Osmond RI, Kett WC, Skett SE \& Coombe DR 2002 Protein-heparin interactions measured by BIAcore 2000 are affected by the method of heparin immobilization. Analytical Biochemistry 310 199-207.

Parker A, Clarke JB, Busby WH Jr \& Clemmons DR 1996 Identification of the extracellular matrix binding sites for insulinlike growth factor-BP 5. Fournal of Biological Chemistry 271 13523-13529.

Phillips K, Park MA, Quarrie LH, Boutinaud M, Lochrie JD, Flint DJ, Allan GJ \& Beattie J 2003 Hormonal control of IGF-BP (IGFBP)-5 and IGFBP-2 secretion during differentiation of the HC11 mouse mammary epithelial cell line. Foumal of Molecular Endocrinology 31 197-208.
Sakai K, D'Ercole AJ, Murphy LJ \& Clemmons DR 2001 Physiological differences in insulin-like growth factor BP-1 (IGFBP-1) phosphorylation in IGFBP-1 transgenic mice. Diabetes 50 32-38.

Sasaki H, Hayashi A, Kitagaki-Ogawa H, Matsumoto I \& Seno N 1987 Improved method for the immobilization of heparin. Fournal of Chromatography $\mathbf{4 0 0}$ 123-132.

Schedlich LJ, Le Page SL, Firth SM, Briggs LJ, Jans DA \& Baxter RC 2000 Nuclear import of insulin-like growth factor-BP-3 and -5 is mediated by the importin beta subunit. Fournal of Biological Chemistry 275 23462-23470.

Schneider MR, Wolf E, Hoeflich A \& Lahm H 2002 IGF-BP-5: flexible player in the IGF system and effector on its own. Fournal of Endocrinology 172 423-440.

Shand JH, Beattie J, Song H, Phillips K, Kelly SM, Flint DJ \& Allan GJ 2003 Specific amino acid substitutions determine the differential contribution of the $\mathrm{N}$ - and C-terminal domains of insulin-like growth factor (IGF)-BP-5 in binding IGF-I. Foumal of Biological Chemistry 278 17859-17866.

Song H, Beattie J, Campbell IW \& Allan GJ 2000 Overlap of IGFand heparin-binding sites in rat IGF-BP-5. Fournal of Molecular Endocrinology 24 43-51.

Song H, Shand JH, Beattie J, Flint DJ \& Allan GJ 2001 The carboxy-terminal domain of IGF-BP-5 inhibits heparin binding to a site in the central domain. Fournal of Molecular Endocrinology 26 229-239.

Tonner E, Barber MC, Travers MT, Logan A \& Flint DJ 1997 Hormonal control of insulin-like growth factor-BP-5 production in the involuting mammary gland of the rat. Endocrinology 138 5101-5107.

Twigg SM, Kiefer MC, Zapf J \& Baxter RC 1998 Insulin-like growth factor-BP 5 complexes with the acid-labile subunit. Role of the carboxyl-terminal domain. Fournal of Biological Chemistry 273 28791-28798.

Twigg SM, Kiefer MC, Zapf J \& Baxter RG 2000 A central domain binding site in insulin-like growth factor BP-5 for the acid-labile subunit. Endocrinology $141454-457$.

Vorwerk P, Hohmann B, Oh Y, Rosenfeld RG \& Shymko RM 2002 Binding properties of insulin-like growth factor BP-3 (IGFBP-3), IGFBP-3 N- and C-terminal fragments, and structurally related proteins mac25 and connective tissue growth factor measured using a biosensor. Endocrinology 143 1677-1685.

Wong MS, Fong CC \& Yang M 1999 Biosensor measurement of the interaction kinetics between insulin-like growth factors and their BPs. Biochimica et Biophysica Acta 1432 293-301.

\section{Received 9 September 2004} Accepted 15 November 2004 